\title{
Estimating the Potential Success of Sustainable Transport Measures for a Small Town
}

\author{
Séona Farrell, David McNamara, and Brian Caulfield
}

\begin{abstract}
This paper examines the benefits of promoting and encouraging the use of soft modes of transport in a small town in Ireland. Currently, in the town in question, almost 70\% drive to work alone each day. The Irish government recently adopted a policy of actively promoting and developing sustainable towns through the use of soft transport measures. This paper takes a typical town in Ireland and demonstrates how a modal shift toward sustainable transport measures could result in substantial savings in vehicle kilometers traveled and carbon dioxide $\left(\mathrm{CO}_{2}\right)$ emissions. Census data were used to estimate the benefits of a modal shift from driving alone to walking, cycling, and carpooling. The COPERT IV model was used to estimate the reductions in $\mathrm{CO}_{2}$ emissions if the estimated modal shifts were realized. Analysis of the commuting patterns of the individuals in the study area shows that the majority of car trips are less than $6 \mathrm{~km}$. The results of the paper show that no one soft measure promoted in isolation is the silver bullet; rather, a mix of these options would be optimal for achieving a modal shift.
\end{abstract}

In Ireland, as in many other countries throughout the world, traffic levels are increasing. In 2006, the rate of private car ownership per 1,000 population increased by $3.2 \%$, resulting in an increase in car density to 420 cars per 1,000 population. In comparison, the average for the 25 nations of the European Union (EU) is 476 and the average for the United Kingdom is 469 (1). Over the period from 2000 to 2006 , the total mileage by all private cars increased by $30 \%$, with the increase being $24 \%$ for petrol-powered cars and $56 \%$ for diesel fuel-powered cars (1).

Many factors have contributed to this situation, including increasing rates of car ownership and numbers of drivers, reductions in car occupancy levels, changes in fuel prices, and various levels of spending on roads. The cumulative effects of continually increasing traffic levels in urban areas are now causing serious economic, environmental, and social problems.

One of the most direct implications of the increase in road traffic is the effect on the environment. Concerns about the environmental impacts of road transport have grown. In many urban areas, the private car is the single greatest polluter, predominantly because of the accumulation of vehicles on the road. In Ireland, emissions of

S. Farrell, Waterman Boreham Ltd., Harcourt Centre, 4th Floor, Block 2, Harcourt Street, Dublin 2, Ireland. D. McNamara and B. Caulfield, Department of Civil, Structural, and Environmental Engineering, Trinity College Dublin, Museum Building, Dublin 2, Ireland. Corresponding author: B. Caulfield, brian.caulfield@tcd.ie.

Transportation Research Record: Journal of the Transportation Research Board, No. 2163, Transportation Research Board of the National Academies, Washington, D.C., 2010, pp. 97-102.

DOI: 10.3141/2163-11 carbon dioxide $\left(\mathrm{CO}_{2}\right)$ from fossil fuel combustion accounted for $68.6 \%$ of total greenhouse gas emissions in 2007, whereas that proportion was $58.5 \%$ in 1990 (2). Furthermore, between 1990 and 2007, the greatest increase in $\mathrm{CO}_{2}$ emissions $(178 \%)$ was from the transport sector. Transport continues to be the dominant sector contributing to the growth in $\mathrm{CO}_{2}$ emissions, with emissions being 650,000 tonnes of $\mathrm{CO}_{2}$ equivalents higher in 2007 than in 2006. In particular, road transport accounts for $97 \%$ of the emissions from the transport sector (2).

The general economic prosperity, increasing population, and consequent increasing vehicle numbers, as well as the trend toward the purchase of larger vehicles and the reliance on private cars, particularly in relation to commuting to and from work, have been attributed to be the main factors contributing to the increase in emissions from the transport sector over the last 17 years. In addition, another major factor has been the rapidly growing road freight transport sector (i.e., light-duty and heavy-duty vehicles), with high levels of construction activity also being a major influencing factor (2).

With the forecasted growth in traffic and the requirement for Ireland to meet its obligations both under the Kyoto Protocol and under the EU 2020 binding targets, targeted local and national measures that strive to reduce traffic and its environmental impacts rather than measures that just restrain traffic growth must be implemented. This is reiterated by Hickman and Banister, who argue that meeting national Kyoto Protocol reduction targets will require an integrated package of behavioral policy measures to ensure that travel is conducted in a more carbon emissions-efficient way (3).

In February 2009, the Department of Transport of Ireland launched the Smarter Travel-A Sustainable Transport Future program, which sets out an action plan containing a target of getting 500,000 more people walking, cycling, using public transport, and leaving their cars at home between now and 2020 (4). With this action plan, the government aims to change the transport mix in Ireland so that by 2020 the car use mode share for commuting is reduced from the current level of $65 \%$ to one of $45 \%$. In essence, a range of policies and measures that will facilitate progress toward integrating sustainability considerations into transport policy and, in particular, address the transport emissions issue will be implemented.

Stemming from the Smarter Travel program, the Department of Transport launched Ireland's first national Cycle Policy Framework in April 2009 (5). This new cycle policy document details 109 individual but integrated actions that will be taken over the coming 12 years to deliver a culture of safe cycling in Ireland by 2020. The department envisions a strong cycling culture in Ireland in which all cities, towns, villages, and rural areas will be bicycle friendly. "A culture of cycling will have developed in Ireland to the extent that $10 \%$ of all trips will be by bike by 2020 " (5). 
In 1986, $7 \%$ of all trips to work in Ireland were made by bicycle. However, by 1996 that figure had fallen to just over 4\%, and by 2006 the rate of commuter cycling had fallen to less than $2 \%$. In 1986 , $13 \%$ of all commute trips were on foot; by 2006 this had decreased to $11 \%$ (6). If action is not taken to address these statistics, car use will continue to increase and the commuter walking and cycling modal shares will continue to decline. Car ownership could increase to beyond EU average levels, with the total number of private cars licensed in Ireland possibly increasing from $1,800,000$ to $2,470,000$ (4).

In July 2009, the Department of Transport launched a $€ 50$ million (\$54 million) national competition aimed at funding and delivering innovative examples of sustainable travel in urban and rural areas right around the country. Smarter Travel areas will provide an opportunity to demonstrate the benefits of sustainable transport, promoting and encouraging walking and cycling, and reducing car travel by improving travel facilities and promoting and encouraging behavioral change.

As walking and cycling are zero-carbon-emission activities with no fuel requirements, they can be adopted as part of an overall strategy to reduce car travel and thus reduce the emissions of $\mathrm{CO}_{2}$ and other greenhouse gases. In 2004, the Department for Transport of the United Kingdom published a walking and cycling action plan that set out measures to increase the levels of active travel across England (7). Fifty case studies from that action plan have all shown significant improvements with often modest, but carefully selected initiatives. These schemes have improved local conditions for walking and cycling and have encouraged people to walk and cycle and have provided clear benefits: reduced congestion, improved public health, and enhanced quality of local streets and spaces (8).

For example, Addenbrooke's Hospital in eastern England invested in carsharing and pool cars, ran promotional events for bus travel, improved the walking and cycling infrastructure, and worked with the main local bus operator on the Quality Bus Partnership. The impact of their workplace travel plan has been significant. For example, between 1993 and 2003, the rate of car use fell from 74\% to $42 \%$, that of bus travel rose from $4 \%$ to $23 \%$, that of cycling went up from $17 \%$ to $25 \%$, and that of walking went from $4 \%$ to $7 \%$ (8).

The promotion of carsharing in conjunction with other modes, such as public transport, is another approach advocated to reduce oil dependence problems (9). Reductions in journey times and vehicle kilometers traveled (VKT), shared fuel costs, and decreases in emissions may be achieved by encouraging ridesharing (10). Jacobson and King examined the potential fuel savings in the United States if a policy of ridesharing were promoted (11). It has been suggested that if $10 \%$ of cars were to have more than one passenger, the result could be annual fuel consumption savings of 5.4\%. In 2005, the International Energy Agency examined the potential benefits of promoting ridesharing in Organisation for Economic Co-operation and Development countries and found that by adding one person to every commute trip, the result would be fuel consumption savings of $7.7 \%$, or 5,073,000 barrels of oil a day, and VKTs would be reduced by $12.5 \%$ (12). Caulfield found that carsharing in Dublin, Ireland, accounts for $4 \%$ of all trips to work and results in an annual VKT savings of 68 million $\mathrm{km}$ (13).

This paper does not address the potential mix of cycling-walking and other mobility management policies, for example, measures to improve the walking and cycling environment, improved facilities for walkers and cyclists, or measures to influence travel behavior. Rather, it focuses on the potential benefits should an optimal mix of policies be adopted.

\section{METHODOLOGY}

\section{Data}

The census data used in this paper were taken on the night of Sunday, April 23, 2006, from 1.5 million Irish homes, which had received the census forms 2 weeks before that. The data used here were taken from the place-of-work census of the anonymous records (POWCAR) data set (14). The POWCAR data set contains information on the regular work trips of 1,834,472 individuals in Ireland. Table 1

TABLE 1 Details of Variables Examined

\begin{tabular}{|c|c|}
\hline Variable & Definition \\
\hline \multicolumn{2}{|l|}{ Distance $(\mathrm{km})$} \\
\hline $0-5$ & $=1$ if $0-5$ \\
\hline $6-10$ & $=1$ if $6-10$ \\
\hline $11-15$ & $=1$ if $11-15$ \\
\hline $16-20$ & $=1$ if $16-20$ \\
\hline $21-30$ & $=1$ if $21-30$ \\
\hline $31-40$ & $=1$ if $31-40$ \\
\hline $41+$ & (reference category = distance: $41+\mathrm{km}$ ) \\
\hline \multicolumn{2}{|l|}{ Travel Time (min) } \\
\hline $0-5$ & $=1$ if $0-5$ \\
\hline $6-10$ & $=1$ if $6-10$ \\
\hline $11-20$ & $=1$ if $11-20$ \\
\hline $21-30$ & $=1$ if $21-30$ \\
\hline $31-40$ & $=1$ if $31-40$ \\
\hline $41-50$ & $=1$ if $41-50$ \\
\hline$\underline{51+}$ & (reference category $=$ travel time: $51+$ mins) \\
\hline \multicolumn{2}{|l|}{ Age } \\
\hline $15-24$ & $=1$ if $15-24$ \\
\hline $25-34$ & $=1$ if $25-34$ \\
\hline $35-44$ & $=1$ if $35-44$ \\
\hline $45-54$ & $=1$ if $45-54$ \\
\hline $55-64$ & $=1$ if $55-64$ \\
\hline $65-74$ & $=1$ if $65-74$ \\
\hline $75+$ & (reference category = age: $75+$ ) \\
\hline \multicolumn{2}{|l|}{ Gender } \\
\hline Male & $=1$ if male \\
\hline Female & (reference category = gender: female) \\
\hline \multicolumn{2}{|l|}{ Socioeconomic Group } \\
\hline Employers and managers & $=1$ if employers and managers \\
\hline Higher professional & $=1$ if higher professional \\
\hline Lower professional & $=1$ if lower professional \\
\hline Nonmanual & $=1$ if nonmanual \\
\hline Manual skilled & $=1$ if manual skilled \\
\hline Semiskilled & $=1$ if semiskilled \\
\hline Unskilled & $=1$ if unskilled \\
\hline Self-employed & $=1$ if self-employed \\
\hline Farmers & $=1$ if farmers \\
\hline Agricultural workers & $=1$ if agricultural workers \\
\hline Other & $\begin{array}{l}\text { (reference category = socioeconomic group: } \\
\text { other) }\end{array}$ \\
\hline
\end{tabular}


presents the structure of the data contained in the POWCAR data set. Unfortunately, the income levels of the respondents are not included in the data set, because income is an important factor in the analysis of the travel behaviors of individuals. The objective of the study described in this paper is therefore to examine the impact of the softer measures adopted in a small town. A small town with a population of just over 25,000 inhabitants was chosen as the study area. Each day, more than 7,500 individuals commute into the study area to work.

\section{Model Formulation}

The model estimated in this paper examines the characteristics of the individuals who drive to work in the study area. A number of activity variables, such as travel time and distance and departure times, are examined in the first set of models. A multinomial logistic regression analysis was constructed to analyze the relationship between these factors and people who indicated that they drove to work on a regular basis. The model takes the following functional form:

$\operatorname{logit}(p)=\log \frac{p}{1-p} \equiv a+\beta I+\gamma H+e$

where

$$
\begin{aligned}
& p=\text { probability that event } Y \text { (driving to work) occurs, } \\
& a=\text { specified option, }
\end{aligned}
$$

$$
\begin{aligned}
\beta I & =\text { set of individual-specific characteristics, } \\
\gamma H & =\text { set of household-specific characteristics, and } \\
e & =\text { random error term. }
\end{aligned}
$$

Table 1 details each of the variables estimated in the regression model. All of the variables detailed in Table 1 are dummy variables. The COPERT IV model was used to estimate the reductions in emissions. The details about the private fleet of vehicles used to estimate the savings in $\mathrm{CO}_{2}$ emissions were taken from the government vehicle registration records (15). Monthly average temperatures for 2006 were also inputted into the model.

\section{RESULTS}

This section of the paper presents the results of the analysis conducted to measure the benefits of promoting a number of soft measures in the study area. The results examine the benefits of these soft measures according to the number of VKT saved and the annual $\mathrm{CO}_{2}$ emissions saved. This section of the paper also examines the individuals most likely to drive to work in the study area.

\section{Details of Study Area}

\begin{tabular}{|c|c|c|c|c|c|c|c|c|}
\hline Mode & $N$ & $\%$ & $\begin{array}{l}\text { Mean } \\
\text { Distance } \\
(\mathrm{km})\end{array}$ & $\begin{array}{l}\text { Standard } \\
\text { Deviation- } \\
\text { Distance }(\mathrm{km})\end{array}$ & $\begin{array}{l}\text { Mode- } \\
\text { Distance } \\
(\mathrm{km})\end{array}$ & $\begin{array}{l}\text { Mean Travel } \\
\text { Time (min) }\end{array}$ & $\begin{array}{l}\text { Standard } \\
\text { Deviation- } \\
\text { Time (min) }\end{array}$ & $\begin{array}{l}\text { Mode-Time } \\
(\min )\end{array}$ \\
\hline \multicolumn{9}{|l|}{ Study Area } \\
\hline Walk & 1,105 & 14.7 & 1.76 & 1 & 1 & 14 & 10 & 9 \\
\hline Cycle & 88 & 1.2 & 2.49 & 1.6 & 2 & 12 & 6 & 10 \\
\hline Motorcycle & 25 & 0.3 & 10.95 & 10.3 & 2 & 16 & 11 & 10 \\
\hline Driving & 5,181 & 68.8 & 15.92 & 14.9 & 2 & 23 & 17 & 10 \\
\hline Driving-passenger & 514 & 6.7 & 10.67 & 12.6 & 3 & 18 & 14.3 & 10 \\
\hline Lorry or van & 305 & 4.0 & 17.06 & 15.4 & 2 & 26 & 23.7 & 15 \\
\hline Other means & 12 & 0.2 & NA & NA & NA & NA & NA & NA \\
\hline Work from home & 38 & 0.5 & NA & NA & NA & NA & NA & NA \\
\hline Total & 7,536 & 100.0 & NA & NA & NA & NA & NA & NA \\
\hline \multicolumn{9}{|l|}{ National } \\
\hline Walk & 197,622 & 10.9 & 1.82 & 1.37 & 1 & 15 & 12 & 10 \\
\hline Cycle & 35,310 & 1.9 & 4.83 & 3.84 & 2 & 14 & 12 & 10 \\
\hline Public transport & 164,066 & 9.0 & 12.18 & 15 & 10 & 42 & 27 & 60 \\
\hline Motorcycle & 12,678 & 0.7 & 13.32 & 12.70 & 10 & 24 & 17 & 20 \\
\hline Driving & $1,052,795$ & 58.1 & 16.36 & 16.50 & 10 & 27 & 23 & 10 \\
\hline Driving-passenger & 102,483 & 5.7 & 13.40 & 14.82 & 10 & 23 & 20 & 10 \\
\hline Lorry or van & 138,208 & 7.6 & 21.36 & 19.88 & 10 & 33 & 29 & 30 \\
\hline Other means & 6,228 & 0.3 & NA & NA & NA & NA & NA & NA \\
\hline Work from home & 56,897 & 3.1 & NA & NA & NA & NA & NA & NA \\
\hline NA & 45,634 & 2.5 & NA & NA & NA & NA & NA & NA \\
\hline
\end{tabular}

The first set of results detailed in Table 2 report the modal split of the study area and the national modal split. The mean distance traveled and the mean travel times are also reported in Table 2 . The results

TABLE 2 Modal Split of Morning Commuters into Study Town

NoTE: NA = not applicable. 
show that the majority of individuals in the study area (68.8\%) travel to work by car. The modal share for car is $10.7 \%$ higher than the national average in the study area. The modal share shows that a high percentage of individuals in the study area walk to work on a regular basis. One other result of interest is that $2.9 \%$ of individuals in the study area use public transport to travel to work; this is substantially less than the national figure of $9.0 \%$.

\section{Characteristics of Individuals Who Drive to Work in Study Area}

This section of the paper examines the characteristics of the individuals who drive to work in the study area. Table 3 details the results of a logistic regression analysis used to measure the characteristics of the individuals who drive to work. The first characteristic examined in Table 3 is the distance traveled by those who drive to work. The results show that those who drive to work in the study area are more likely to drive less than $10 \mathrm{~km}$. The results also show that those who drive to work are more likely to have short commuting times (less than $10 \mathrm{~min}$ ). These findings suggest that motorists are more likely to have shorter commuting distances and travel times than those who use alternative modes of transport.

The results for departure time show that positive coefficients were estimated for those individuals who departed between 7:00 and 9:00 a.m. This result suggests that those individuals who drive to work are most likely to depart for work during this time period. The age profile of individuals who drive to work on a regular basis is also examined in Table 3 . The findings suggest that individuals aged between 15 and 24 years are unlikely to drive to work, whereas individuals in the older age groups are more likely to drive to work.

The gender coefficient estimated in Table 3 demonstrates that females are more likely to drive to work. This could be because of other nonwork commitments, such as dropping off children at school, which would require a car. Information on such trips is not included in the data set examined. The final set of variables examined in Table 3 measures how an individual's socioeconomic group is likely to have an impact on driving to work. Each of the occupation variables estimated was found to be positive. The results show that employers and managers, higher professionals, and lower professionals are more likely than the other groups to drive to work. The results presented in Table 3 demonstrate that individuals who drive to work in the study area are most likely to have shorter commuting distances and travel times. This group of individuals was investigated further, as described in the following sections, as their short travel distances may make them ideal candidates for switching to other, more sustainable modes of travel to work.

\section{Distances Driven by Individuals to Work in Study Area}

The distances traveled by individuals who drive to work are shown below. The distances driven to work are segmented into three categories: individuals who travel less than $2 \mathrm{~km}$ to work, those who travel 2 to $6 \mathrm{~km}$ to work, and those who travel more than $6 \mathrm{~km}$. Fourteen percent of individuals who drive to work travel less than $2 \mathrm{~km}$, and $21 \%$ of individuals drive between 2 and $6 \mathrm{~km}$ to get to
TABLE 3 Regression Analysis Results

\begin{tabular}{|c|c|c|}
\hline & Estimate & $p$-Value \\
\hline Intercept & 0.016 & .005 \\
\hline \multicolumn{3}{|l|}{ Distance $(\mathrm{km})$} \\
\hline $0-5$ & 3.374 & .000 \\
\hline $6-10$ & 1.150 & .000 \\
\hline $11-15$ & 0.941 & .000 \\
\hline $16-20$ & 0.535 & .001 \\
\hline $21-30$ & 0.583 & .000 \\
\hline $31-40$ & 0.638 & .000 \\
\hline $41+$ & $0^{a}$ & \\
\hline \multicolumn{3}{|l|}{ Travel time (min) } \\
\hline $0-5$ & 2.268 & .000 \\
\hline $6-10$ & 2.359 & .000 \\
\hline $11-20$ & 1.372 & .001 \\
\hline $21-30$ & 0.960 & .000 \\
\hline $31-40$ & 0.947 & .000 \\
\hline $41-50$ & 1.093 & .000 \\
\hline $51+$ & $0^{a}$ & \\
\hline \multicolumn{3}{|l|}{ Departure time } \\
\hline Before 06:30 & -0.415 & .001 \\
\hline 06:31-07:00 & -0.349 & .001 \\
\hline 07:01-07:30 & -0.040 & .000 \\
\hline 07:31-08:00 & 0.253 & .000 \\
\hline 08:01-08:30 & 0.068 & .000 \\
\hline 08:31-09:00 & 0.635 & .000 \\
\hline 09:01-09:30 & -0.680 & .000 \\
\hline After 09:30 & -0.649 & .000 \\
\hline NA & $0^{a}$ & \\
\hline \multicolumn{3}{|l|}{ Age (years) } \\
\hline $15-24$ & -0.264 & .000 \\
\hline $25-34$ & 0.857 & .000 \\
\hline $35-44$ & 0.996 & .001 \\
\hline $45-54$ & 1.088 & .001 \\
\hline $55-64$ & 1.196 & .000 \\
\hline $65-74$ & 1.977 & .000 \\
\hline $75+$ & $0^{a}$ & \\
\hline \multicolumn{3}{|l|}{ Gender } \\
\hline Male & -0.452 & .000 \\
\hline Female & $0^{a}$ & \\
\hline \multicolumn{3}{|l|}{ Socioeconomic group } \\
\hline Employers and managers & 1.280 & .000 \\
\hline Higher professional & 1.690 & .000 \\
\hline Lower professional & 1.645 & .000 \\
\hline Nonmanual & 0.808 & .000 \\
\hline Manual skilled & 0.170 & .000 \\
\hline Semiskilled & 0.690 & .000 \\
\hline Unskilled & 0.172 & .000 \\
\hline Self-employed & 0.620 & .000 \\
\hline Farmers & 0.809 & .000 \\
\hline Agricultural workers & 0.058 & .000 \\
\hline Other & $0^{a}$ & \\
\hline
\end{tabular}

NoTE: $-2 \log$ likelihood at convergence $=3,574.39 ; N=5,181$; and $R^{2}=.319$.

${ }^{a}$ The values are set equal to zero because they are redundant.

work. In the subsequent analysis, individuals who drive less than $2 \mathrm{~km}$ will be targeted to walk to work, and those who travel between 2 and $6 \mathrm{~km}$ will be targeted to cycle to work.

\begin{tabular}{lrc} 
Distance Driven to Work $(\mathrm{km})$ & \multicolumn{1}{c}{$N$} & Percent \\
$<2$ & 655 & 14 \\
$2-6$ & 1,012 & 21 \\
$>6$ & 3,081 & 65 \\
Total & 4,748 & 100
\end{tabular}


TABLE 4 Potential Benefits for Modal Shift from Drive Alone to Walking

\begin{tabular}{lcc}
\hline & \multicolumn{2}{l}{ Annual Savings } \\
\cline { 2 - 3 } & \multicolumn{2}{c}{$\begin{array}{c}\mathrm{CO}_{2} \text { Emissions } \\
\text { (tonnes) }\end{array}$} \\
\hline Scenario & & \\
5\% modal shift to walking & 23,914 & 4.44 \\
5 days a week & 15,870 & 2.95 \\
4 days a week & 14,348 & 2.67 \\
3 days a week & & \\
10\% modal shift to walking & 47,828 & 8.89 \\
5 days a week & 31,740 & 5.90 \\
4 days a week & 28,969 & 5.38 \\
3 days a week &
\end{tabular}

\section{Examining Benefits of Modal Shift from Driving Alone to Walking to Work}

This section of the paper examines the benefits of a modal shift from driving alone to walking to work on a regular basis. The environmental benefits of a modal shift to walking to work were estimated by using the COPERT IV model. The results in the table above show that $14 \%$ (655) of individuals drive less than $2 \mathrm{~km}$ to work each day. The six scenarios examined (Table 4 ) assume that $5 \%$ or $10 \%$ of those individuals who currently drive less than $2 \mathrm{~km}$ to work alone each day start to walk to work 5,4 , or 3 days a week. The first set of scenarios examined the savings of VKT and $\mathrm{CO}_{2}$ emissions if $5 \%$ of individuals who currently drive less than $2 \mathrm{~km}$ walked to work 5 , 4, or 3 days a week. The results in Table 4 show that modest annual $\mathrm{CO}_{2}$ emissions savings would occur if a 5\% modal shift toward walking occurred. Furthermore, substantial annual VKT could be saved if a modal shift toward walking occurred.

The second set of scenarios examined in Table 4 measures the impact of a $10 \%$ modal shift from driving alone to walking to work. The results show, as one would expect, that a greater annual $\mathrm{CO}_{2}$ emissions savings, as well as greater savings in VKT, would be realized with a $10 \%$ modal shift.

\section{Examining Benefits of Modal Shift from Driving Alone to Cycling to Work}

The benefits of a modal shift from driving alone to cycling to work are presented in Table 5. The scenarios examined in this

TABLE 5 Potential Benefits for Modal Shift from Drive Alone to Cycling

\begin{tabular}{llc}
\hline & \multicolumn{2}{l}{ Annual Savings } \\
\cline { 2 - 3 } Scenario & VKT & $\begin{array}{l}\mathrm{CO}_{2} \text { Emissions } \\
\text { (tonnes) }\end{array}$ \\
\hline 5\% modal shift to cycling & & \\
5 days a week & 93,192 & 17.32 \\
4 days a week & 61,845 & 11.49 \\
3 days a week & 55,915 & 10.39 \\
10\% modal shift to cycling & & \\
5 days a week & 186,384 & 34.64 \\
4 days a week & 123,691 & 22.99 \\
3 days a week & 111,830 & 20.78 \\
\hline
\end{tabular}

section of the paper are similar to those examined in the previous section, in that they examine the environmental benefits of a modal shift from driving alone to cycling. The group examined consists of those who drive 2 to $6 \mathrm{~km}$ to work on a regular basis, which, as the table above the shows, comprises $21 \%(n=1,012)$ of the individuals. The COPERT IV model was used to estimate the environmental benefits according to the annual reduction in $\mathrm{CO}_{2}$ emissions.

The results show that if a 5\% modal shift to cycling to work were realized for even part of the week, substantial annual savings in VKT and $\mathrm{CO}_{2}$ emissions could be achieved. The results for a $10 \%$ modal shift from driving alone to cycling were found to be even more savings in VKT and $\mathrm{CO}_{2}$ emissions compared with those achieved with a $5 \%$ modal shift.

\section{Examining Benefits of Modal Shift from Driving Alone to Carpooling}

The final soft measure examined in this study is carpooling in the study area. The data used in this study were segmented by the three electoral districts in the study area with the highest concentrations of individuals who drive alone to work in the town center to ascertain the potential for carpooling. The departure times of the individuals in these three areas were examined and are presented in Table 6. As the individuals in these areas have the same origin, destination, and departure time, the results show that there is the potential for the individuals in each of the areas to carpool.

The results in Table 7 detail the benefits that would be achieved if a percentage of the individuals switched from driving alone to carpooling. As with the previous scenarios for modal shifts to walking and cycling, the results in Table 7 examine the benefits of a 5\% or $10 \%$ modal shift to carpooling 5, 4, or 3 days a week. The results from each of the scenarios show that considerable reductions in annual VKT and annual $\mathrm{CO}_{2}$ emissions can be achieved by switching to carpooling.

\section{DISCUSSION OF RESULTS AND CONCLUSIONS}

The results presented in this paper demonstrate that because of the short commuting distances associated with small towns, they are ideal candidates to be encouraged to use sustainable transport options. Low-cost options such as those examined in this paper are suited to

TABLE 6 Examining Individuals Most Capable of Carpooling

\begin{tabular}{|c|c|c|c|c|c|c|}
\hline \multirow[b]{2}{*}{ Departure Time } & \multicolumn{2}{|l|}{ Area 1} & \multicolumn{2}{|c|}{ Area 2} & \multicolumn{2}{|c|}{ Area 3} \\
\hline & $N$ & $\%$ & $N$ & $\%$ & $N$ & $\%$ \\
\hline Before 06:30 & 28 & 2 & 6 & 3 & 2 & 1 \\
\hline 06:31-07:00 & 56 & 3 & 7 & 4 & 4 & 2 \\
\hline 07:01-07:30 & 82 & 5 & 6 & 3 & 17 & 11 \\
\hline 07:31-08:00 & 189 & 12 & 24 & 13 & 27 & 17 \\
\hline 08:01-08:30 & 337 & 21 & 34 & 18 & 51 & 32 \\
\hline 08:31-09:00 & 493 & 30 & 63 & 34 & 37 & 23 \\
\hline 09:01-09:30 & 229 & 14 & 29 & 16 & 12 & 7 \\
\hline After-09:30 & 164 & 10 & 16 & 9 & 10 & 6 \\
\hline NA & 61 & 4 & 2 & 1 & 1 & 1 \\
\hline Total & 1,639 & 100 & 187 & 100 & 161 & 100 \\
\hline
\end{tabular}


TABLE 7 Potential Benefits for Modal Shift from Drive Alone to Rideshare

\begin{tabular}{|c|c|c|}
\hline \multirow[b]{2}{*}{ Scenario } & \multicolumn{2}{|c|}{ Annual Savings } \\
\hline & VKT & $\begin{array}{l}\mathrm{CO}_{2} \text { Emissions } \\
\text { (tonnes) }\end{array}$ \\
\hline \multicolumn{3}{|c|}{$5 \%$ modal shift to rideshare } \\
\hline 5 days a week & 80,395 & 14.94 \\
\hline 4 days a week & 64,316 & 11.95 \\
\hline 3 days a week & 48,237 & 8.96 \\
\hline \multicolumn{3}{|c|}{$10 \%$ modal shift to rideshare } \\
\hline 5 days a week & 161,275 & 29.97 \\
\hline 4 days a week & 129,020 & 23.98 \\
\hline 3 days a week & 96,765 & 17.89 \\
\hline
\end{tabular}

smaller towns, where the financial resources to operate or construct traditional transport alternatives may not exist.

The findings of this study show that use of a combination of soft measures can result in substantial environmental benefits. The potential for a modal shift for individuals who are within walking and cycling distances to the town center was examined. Individuals who are assumed to carpool reside in areas where there is a significant potential to find a carpooling partner. The results of the scenarios estimated in this paper show that if a modal shift were to occur, substantial savings in emissions and VKT would result.

On the basis of the findings presented here, it is clear that no one soft measure would result in substantial changes in transport-related emissions or VKT. If a combination of walking, cycling, and car pooling were adopted in the study area, as described here, the result would be considerable benefits to the environment.

\section{ACKNOWLEDGMENT}

The authors thank the Central Statistics Office of Ireland for providing the data for this study.

\section{REFERENCES}

1. Energy in Transport 2007 Report. Sustainable Energy Ireland, Dublin, 2007.

2. Irelands Greenhouse Gas Emissions in 2007. Environmental Protection Agency, Wexford, Ireland, 2008.

3. Hickman, R., and D. Banister. Looking over the Horizon: Transport and Reduced $\mathrm{CO}_{2}$ Emissions in the UL by 2030. Transport Policy, Vol. 14, 2007, pp. 377-387.

4. Smarter Travel-A Sustainable Transport Future. Department of Transport, Dublin, Ireland, 2009.

5. Ireland's First National Cycle Policy Framework. Department of Transport, Dublin, Ireland, 2009.

6. Census 2006, Vol. 12. Travel to Work, School and College. Central Statistics Office, Dublin, Ireland, 2007.

7. Department for Transport. Walking and Cycling: An Action Plan. Department for Transport, London, 2004

8. Department for Transport. Encouraging Walking and Cycling: Success Stories. Department for Transport, London, 2005.

9. Sovacool, B. K. Solving the Oil Independence Problem: Is It Possible? Energy Policy, Vol. 35, 2007, pp. 5505-5514.

10. Fellows, N. T., and D. E. Pitfield. An Economic and Operational Evaluation of Urban Car-Sharing. Transportation Research Part D, Vol. 5 , 2000, pp. 1-10.

11. Jacobson, S. H., and D. M. King. Fuel Saving, and Ridesharing in the US Motivations, Limitations, and Opportunities. Transportation Research Part D, Vol. 14. 2009, pp. 14-21.

12. Saving Oil in a Hurry: Measures for Rapid Demand Restraint in Transport. Draft Report. International Energy Agency, Organisation for Economic Co-operation and Development, Paris, 2005.

13. Caulfield, B. Estimating the Benefits of Ride-Sharing: A Case Study of Dublin. Transportation Research Part D, Vol. 14, 2009, pp. 527-531.

14. Census of Population of Ireland 2006. Place of Work, Census of Anonymised Records (POWCAR) Users Guide. Central Statistics Office, Dublin, Ireland, 2007

15. Department of the Environment, Heritage, and Local Government. Irish Bulletin of Vehicle and Driver Statistics 2003. Government Publications, Dublin, Ireland, 2004.

The views expressed in this paper are those of the authors and do not necessarily reflect those of Waterman Boreham $L$ td.

The Transportation and Sustainability Committee peer-reviewed this paper. 